\title{
Nondestructive Measurement of Momentum Transfer Collision Frequency for Low Temperature Combustion Plasma
}

\author{
Douglas Letsholathebe, Kgakgamatso M. Mphale, and Samuel Chimidza \\ Physics Department, University of Botswana, P/Bag 0022, Gaborone, Botswana \\ Correspondence should be addressed to Douglas Letsholathebe; darkieww@yahoo.com
}

Received 25 October 2013; Accepted 27 December 2013; Published 18 February 2014

Academic Editor: Vincenzo Galdi

Copyright ( 2014 Douglas Letsholathebe et al. This is an open access article distributed under the Creative Commons Attribution License, which permits unrestricted use, distribution, and reproduction in any medium, provided the original work is properly cited.

\begin{abstract}
Accurately measured momentum transfer collision frequency and electron density for fire plasma enable correct simulation of electromagnetic wave propagation in the medium. The simulation is essential for designing high-performance systems suitable for the environment. Despite this, momentum transfer collision frequency for fire plumes has always been an estimated quantity and/or crudely determined. There are anecdotal reports of severe line-of-sight (LOS) radio frequency signal degradation on firegrounds. The problem has implications on safety of fire-fighters during wildfire suppression hence the need of high performance communication systems. In the experiment, a nonintrusive and direct method for measuring momentum transfer collision frequency in a fire plume was carried out. Using an automatic network analyser, $x$-band microwaves were caused to propagate combustion zones of eucalyptus and grass litter fires to measure the flames, scattering parameters. The parameters were then used to determine average collision frequencies for the plumes. The average collision frequencies for the eucalyptus and grass fire plumes were measured to be $5.84 \times 10^{10}$ and $5.92 \times 10^{10} \mathrm{rad} / \mathrm{s}$, respectively.
\end{abstract}

\section{Introduction}

Large high intensity wildfires are a recurring phenomenon in eucalyptus dominated forests of temperate south-eastern Australia and southern California shrublands $[1,2]$. Antecedent climate under which the fires burn is often characterised by the occurrence of El-Niño Southern Oscillation (ENSO) related drought and persistent hot dry winds which sweep through the ecosystems making them fire prone [3]. When ignited under extreme fire weather, the dehydrated vegetation burns into large high intensity wildfires which are a threat to human lives and property at urban-wildland interfaces. At times, the wildfires result in tragic loss of human lives and properties worth millions of dollars, for example, Black Saturday fire incident (see [4]). Under such apprehensive situations, reliable radio communications systems which are capable of operating under severe atmospheric conditions are essential for distribution of information among firefighters. Despite this, there are anecdotal reports of failure to maintain LOS radio frequency communication through large wildfire plumes [5]. This is a safety concern for fire-fighters on the fireground.

Accurate knowledge of radio wave propagation characteristics in a fire plume is essential for designing highperformance systems suitable for the environment [6]. Since the early 1970s, a significant amount of research on propagation measurements of radio waves in vegetation fire plumes has been done, for example, [5, 7-10]. However, carrying out such measurements is time consuming and expensive. Nevertheless, the propagation data and simulation schemes are needed for performance evaluation of the systems. Hitherto, very little research has been done on simulation modelling of radio wave propagation characteristics in fire, for example, $[11,12]$.

A fire plume is weakly ionised atmospheric pressure low temperature combustion plasma which is highly collisional [5]. Collision frequency is a crucial electromagnetic constitutive parameter for radio frequency propagation in the medium [13]. In spite of this, accurate determination of the parameter is still a challenge. Several methods have been used 
to determine the momentum transfer collision frequency in flames. They include the use of (a) graphical methods, for example, [14]; (b) interferometry (attenuation and phase change measurements), for example, [13]; and (c) expressions derived from the kinetic theory, for example, $[10,15,16]$. The graphical method is error prone [14]. The kinetic theory based expressions often lead to conflicting values of momentum transfer collision frequency at any particular temperature and hence leading to order of magnitude errors in the prediction of signal attenuation.

The objective of the experiment is to provide a quick, nonintrusive, and accurate method for determining momentum transfer collision frequency for fire plasma using an automatic network analyser. In the experiment, scattering parameters $\left(S_{21}\right.$ and $\left.S_{11}\right)$ were measured using an automatic network analyser and uploaded into a computer for analysis. A MATLAB program was written to extract complex relative dielectric permittivity from the scattering parameters and momentum transfer collision frequency determined from the imaginary and real parts of the relative dielectric permittivity. The theory pertinent to the method is discussed in Section 2. Section 3 of the paper discusses some of the theoretical equations used for calculation momentum collision frequency. Results of the measured collision frequencies are discussed in Section 5.

\section{Theoretical Considerations}

2.1. Momentum Transfer Collision Frequency. Consider a homogeneous, nonmagnetised weakly ionised fire plume which is illuminated with a low intensity electric field, $\mathbf{E}=$ $\mathbf{E}_{0} e^{i \omega t-\gamma \cdot x}$, propagating in the $x$-direction. The Boltzmann equation for electrons in the plume is given as [17]

$$
\frac{\partial f}{\partial t}+\frac{q_{e} \mathbf{E}}{m_{e}} \frac{\partial f}{\partial v}=\left\{\frac{\partial f}{\partial t}\right\}_{\text {coll }} .
$$

The right-hand side of (1) represents change in the distribution function by elastic and inelastic collisional processes.

Expanding the distribution function, $f$, into a Legendre polynomial of the variable $\cos \theta$ and neglecting second and higher order terms, we then have

$$
f=f_{0}+\mathbf{f}_{1} \cdot \cos \boldsymbol{\theta}+\cdots,
$$

where $\cos \theta=\mathbf{v} / v$. The symmetric part of the expansion in (2), $f_{0}$, is a Maxwellian distribution function given by

$$
f_{0}=N_{e}\left\{\frac{m_{e}}{2 \pi k_{B} T_{f}}\right\}^{3 / 2} \exp \left(\frac{-m_{e} v^{2}}{2 \pi k_{B} T_{f}}\right) .
$$

The asymmetric part, $f_{1}$, is deviation from $f_{0}$ due to an increase in electron velocity.

On Substituting (2) into (1) and integrating over the entire phase space gives [18]

$$
\mathbf{f}_{1}=-\frac{q_{e} \mathbf{E}}{m_{e}(\varphi+i \omega)} \frac{\partial f_{0}}{\partial v} .
$$

Current density due to the electrons in the plume $(\mathbf{J})$ is given by [18] as

$$
\mathbf{J}=\frac{4 \pi q_{e}}{3} \int_{0}^{\infty} v^{3} \mathbf{f}_{1} d v
$$

From Ohm's Law, current density is related to electrical conductivity $(\sigma)$ by the relation:

$$
\mathbf{J}=\sigma \mathbf{E} .
$$

Therefore, complex electrical conductivity can then be deduced from (4) to (6) to be in the form:

$$
\sigma=\frac{4 \pi}{3 m_{e}} q_{e}^{2} \int_{0}^{\infty} \frac{d}{d v}\left\{\frac{v^{3}}{\varphi+i \omega}\right\} f_{0} d v .
$$

Let $\delta=v /\left(2 k_{B} T_{f} / m_{e}\right)^{1 / 2}$ and substituting (3) into (7) gives

$$
\sigma=\frac{8 N_{e} q_{e}^{2}}{3 m_{e} \pi^{1 / 2}}\left\{\int_{0}^{\infty} \frac{1}{\varphi+i \omega} \delta^{4} e^{-\delta^{2}} d \delta\right\} .
$$

Noting that $\int_{0}^{\infty} \delta^{4} e^{-\delta^{2}} d \delta=(3 / 8)(\pi)^{1 / 2}$ and assuming that $\varphi$ is independent of particle velocity in fire plasma as in [19], then the expression for conductivity (see (8)) reduces to the Lorentz-Drude Conductivity Equation:

$$
\sigma=\sigma^{\prime}+i \sigma^{\prime \prime}=\frac{N q_{e}^{2}}{m_{e}\left(\varphi^{2}+\omega^{2}\right)}[\varphi-i \omega] .
$$

The real and imaginary parts of conductivity are related to relative dielectric permittivity $\left(\varepsilon_{r}\right)$ by the expression [17];

$$
\varepsilon_{r}=\varepsilon^{\prime}-i \varepsilon^{\prime \prime}=\left\{1+\frac{\sigma^{\prime}}{i \omega \varepsilon_{0}}+\frac{\sigma^{\prime \prime}}{\omega \varepsilon_{0}}\right\} .
$$

On substituting the real and imaginary parts of conductivity from (9) into (10) and simplifying after rearranging (10) gives electron-neutral particle momentum transfer collision frequency for the fire plasma as

$$
\varphi=\omega\left\{\frac{\varepsilon^{\prime \prime}}{1-\varepsilon^{\prime}}\right\} .
$$

The real and imaginary parts of relative dielectric permittivity for the plasma can be measured using an automatic network analyser.

2.2. Scattering Parameters and Relative Permittivity. Propagation factor $(P)$ is related to the relative dielectric permittivity $\left(\varepsilon_{r}\right)$, reflection, and transmission scattering parameters $\left(S_{11}\right.$ and $S_{21}$, resp.) by the following expression [10]:

$$
P=\exp \left\{-i \frac{\omega}{c}\left(\sqrt{\varepsilon_{r}}\right) d\right\}=\left[\frac{S_{11}^{2}+S_{21}^{2}-\Gamma}{1-\left(S_{11}+S_{21}\right) \Gamma}\right] .
$$

Reflection coefficient $(\Gamma)$ is given by the expression, $\Gamma=\chi \pm$ $\sqrt{\chi^{2}-1}$ where $\chi=\left(\left(S_{11}^{2}-S_{21}^{2}+1\right) / 2 S_{11}\right)$. The sign in the expression for $(\Gamma)$ is chosen such that $|\Gamma|<1$.

Following from (12), $\varepsilon_{r}$ for nonmagnetised fire plasma can be determined from the following expression:

$$
\varepsilon_{r}=\varepsilon^{\prime}-i \varepsilon^{\prime \prime}=\lambda_{\operatorname{pr}}\left\{\frac{i}{2 \pi d}\left[\log _{e}\left(\frac{1}{P}\right)\right]\right\}^{2} .
$$


TABLE 1: Momentum transfer collision frequency from relation in the literature.

\begin{tabular}{|c|c|c|c|}
\hline \multirow[b]{2}{*}{ Fire temperature $(\mathrm{K})$} & \multicolumn{3}{|c|}{ Momentum transfer collision frequency equation: } \\
\hline & $\begin{array}{l}\text { Letsholathebe and Mphale, (2013) [10]: } \\
\qquad\left(\times 10^{10} \mathrm{rad} \mathrm{s}^{-1}\right)\end{array}$ & $\begin{array}{c}\text { Uhm, } \\
(1999)[22]: \\
\left(\times 10^{11} \mathrm{rad} \mathrm{s}^{-1}\right)\end{array}$ & $\begin{array}{l}\text { Lu and Laroussi, } \\
(2008)[21]: \\
\left(\times 10^{10} \mathrm{rad} \mathrm{s}^{-1}\right)\end{array}$ \\
\hline 800 & 6.64 & 1.38 & 7.49 \\
\hline 1100 & 5.66 & 1.17 & 6.39 \\
\hline
\end{tabular}

\section{Calculation of Collision Frequency}

For atmospheric pressure plasma, collision frequency is a very important parameter as collisions between charged particles can degrade and shift incident electromagnetic wave by a few wavelengths [20]. The collision frequency is a function of background gas number density, velocity of electrons, and collision cross section of electrons with the background gas. If the background gas is a mixture of gases, then momentum transfer collision cross-section with electrons should be averaged. Thus the average collision cross section is given by the relation:

$$
Q_{\mathrm{av}}=\sum_{i} m_{i} Q_{i}
$$

Average collision frequency for a particular electron velocity is then calculated from the equation [21]:

$$
\varphi=\bar{v} N_{g} Q_{\mathrm{av}},
$$

where $\bar{v}=\left\{2 k_{B} T_{f} / m_{e}\right\}^{1 / 2}$ is thermal velocity of the electrons of the flame gas.

Several authors have used similar relations for the calculation of the momentum transfer collision frequency in flames, for example, $[10,15]$. Letsholathebe and Mphale [10] calculated the parameter from the relation:

$$
\varphi=P D_{g}^{2}\left\{\frac{\pi}{2 k_{B} T_{f} m_{e}}\right\} .
$$

Uhm [22] calculates momentum transfer collision frequency in flame plasma using the equation:

$$
\varphi=1.36 \times 10^{12}\left[\frac{T_{\mathrm{rf}}}{T_{f}}\right] \sqrt{T_{e}},
$$

where $T_{\mathrm{rf}}=300 \mathrm{~K}$ is the reference temperature and $T_{e}$ is fire plasma temperature in $\mathrm{eV}$.

Chen and Liu [15] calculated dielectric permittivity of a flame plasma using the following expression for momentum transfer collision frequency:

$$
\varphi=3.637 \times 10^{-10}\left[\frac{P}{k_{B} \sqrt{T_{f}}}\right] .
$$

Except for (15) and (16), collision frequency relations discussed above have no dependence on neutral gas diameter or collision cross section. A comparison of momentum transfer collision frequency calculated from the expression, (16)-(18), shows a marked deviation from each other (see Table 1) and this has a significant implication on simulation modelling.

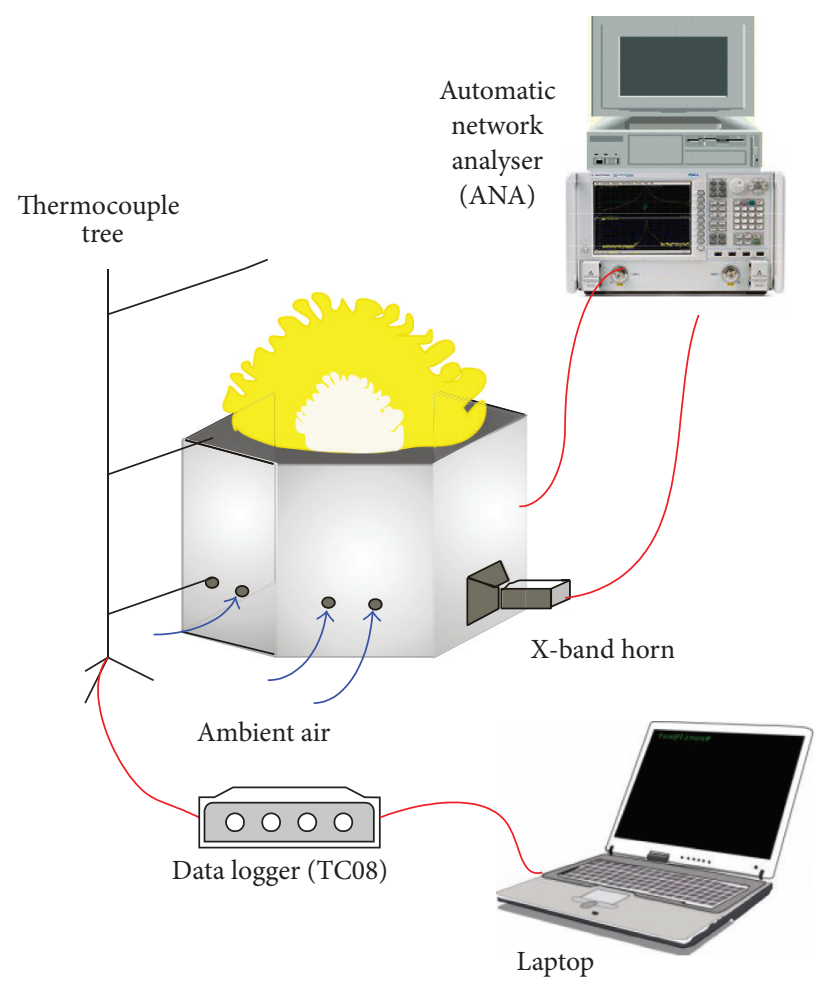

FIGURE 1: Automatic network analyser set up for scattering parameters measurement.

\section{Experimental Setup}

4.1. Hexagonal Combustion Chamber and Analyser System. The equipment used for measuring scattering $(S)$-parameters for the fire is shown in Figure 1. It consisted of a hexagonal combustion chamber, Hewlett-Packard automatic network analyser (HP 8577C) with 8-12 GHz transmit-receive horns and a computer. The horns were connected to the analyser through a two-port $S$-parameter test set by coaxial cables to measure reflection and transmission scattering parameters $\left(S_{11}\right.$ and $\left.S_{21}\right)$. High quality mode transition adapters were used to make the connections between coaxial cables and the horns.

The hexagonal combustion chamber of width $76 \mathrm{~cm}$ was used as fuel bed for Guinea grass (Panicum maximum) and poplar gum (Eucalyptus platyphylla) litter. It was constructed from wood and hexagonally shaped for versatility. The chamber allowed for different combustion base area cross sections, for example, rectangular and circular, to be set. An $8 \mathrm{~cm}$ thick sheet of a good thermal insulating material known as 


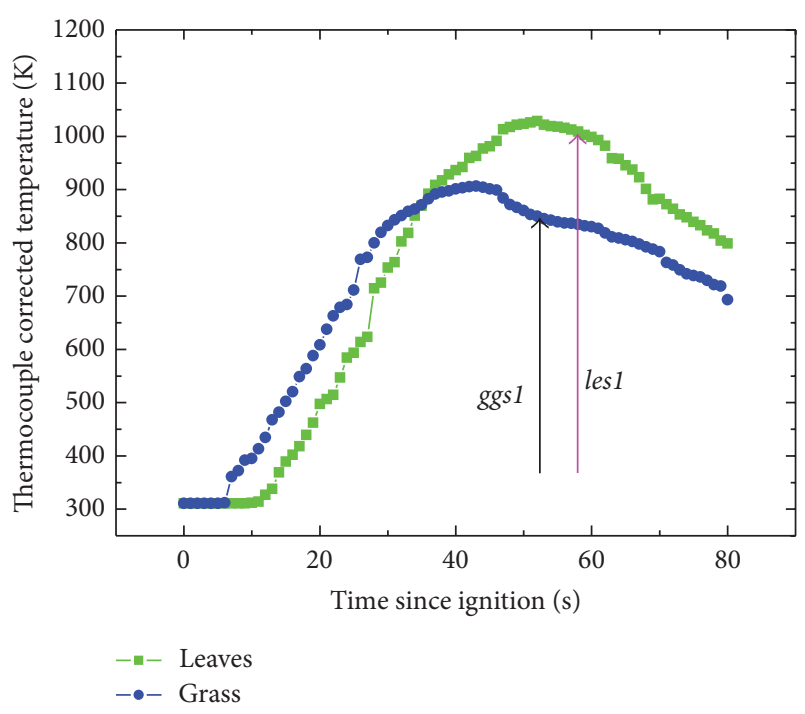

FIGURE 2: Eucalyptus litter fires temperature during the experiment.

Fiberfrax was lined on the inside of the chamber in order to protect the wooden casing from fire. The lining reduced the microwave propagation path length to $52 \mathrm{~cm}$. In the experiment, the Fiberfrax sheet was lined to form a circular base cross section. Two holes of horn antennae dimensions were also cut out from the burner casing, directly opposite to each other. Wooden supports were provided to hold the horns firmly in position during the experiment. Aeration holes of $0.25 \mathrm{~cm}$ in diameter were drilled on each side of the chamber, except the ones with horn inlets, to allow air to enter and mix with fuel during combustion.

The litter used in the experiment was collected and left to dry in the laboratory for two (2) weeks before burning so as to increase combustion efficiency. Same amount of grass and eucalyptus litter (specific gravity $=25.50 \mathrm{~kg} \mathrm{~m}^{-3}$ ) was used for uniformity.

4.2. Temperature Measurement. A thermocouple tree was wired with three Type $\mathrm{K}$ thermocouples as shown in Figure 1. The thermocouples were made from a braided fiberglass insulated chromel-alumel (24-G/G) wire with a diameter of $50 \mu \mathrm{m}$. The wires were electrofused at one end to make perfect junction and then tested for continuity with a multimeter. They were further wrapped with Fiberfrax, leaving only a centimetre $(1 \mathrm{~cm})$ protruding from the tree arm for temperature measurement (see Figure 1). The wrapping was done to protect the insulation from being burnt by fire. The thermocouples were then connected to a PICO Tech TC-O8 data logger to read in temperature into a laptop throughout each experiment.

4.3. S-Parameter Measurement. The analyser was calibrated using Transmit-Reflect-Line (TRL) method described in Baum et al., [23]. It was set to sweep from 8.00 to $10.0 \mathrm{GHz}$, logging in $601 S$-parameter data points. The $S$-parameters were then uploaded to the computer for analysis using a MAT$L A B$ program. The analyser took approximately $2 \mathrm{~s}$ to sample over one sweep, and then there was a latency of about $50 \mathrm{~s}$ before the next sweep could be initiated. Several sweeps and logging in of the $S$-parameters were carried out but those for which flames filled the entire propagation path (by visual inspection) were chosen for $S$-parameter analysis. Two such cases were ggsl and les 1 (see Figure 2), which were in the first $60 \mathrm{~s}$ of the litter combustion.

\section{Results and Discussions}

5.1. Flame Temperatures. The temperatures of the eucalyptus litter samples were logged into the data logger, until the fires got extinguished. It was observed that the samples burnt fiercely in the first $100 \mathrm{~s}$ since ignition and this was the period in which the fires filled the whole propagation path $(52 \mathrm{~cm})$. The poplar gum litter burnt faster $(25 \mathrm{~K} / \mathrm{s})$ than the grass sample to reach a maximum temperature of $1030 \mathrm{~K}$ in $52 \mathrm{~s}$ (see Figure 2). It then burnt at steady rate of $1.9 \mathrm{~K} / \mathrm{s}$ for a period of $8 \mathrm{~s}$ with the flame filling the whole propagation path. After $80 \mathrm{~s}$ the temperature of the poplar gum sample fell to $796 \mathrm{~K}$. The flame was observed to burn less fiercely after this time with temperature decreasing at the rate of $5 \mathrm{~K} / \mathrm{s}$ until it got extinguished after $305 \mathrm{sec}$.

Guinea grass litter burnt at about the same rate as that of the poplar gum even though the latter took slightly longer to flame. The combustion rate of the grass litter was $23 \mathrm{~K} / \mathrm{s}$ and took $43 \mathrm{~s}$ to reach maximum combustion temperature of $908 \mathrm{~K}$ (Figure 2). After $46 \mathrm{~s}$ the grass burnt steadily for $10 \mathrm{~s}$ to reach a temperature of $832 \mathrm{~K}$. S-parameters sampling was done when combustion reached a steady rate and for the grass litter it was done after $55 \mathrm{~s}$ when fire temperature was $839 \mathrm{~K}$.

5.2. Measured Collision Frequency. Using a MATLAB program, real and imaginary components of fire dielectric permittivity were extracted from the $S$-parameters. They were then used in (11) to determine momentum transfer collision frequency. The measured momentum transfer collision frequencies were averaged over the microwave frequency range (8.00 to $10.0 \mathrm{GHz}$ ) and the values were $5.92 \times 10^{10}$ and $5.84 \times$ $10^{10} \mathrm{rad} \mathrm{s}^{-1}$ for grass and eucalyptus litter fires, respectively (Figures 3 and 4). It is noteworthy that the temperature for the leaf fire les1 was the highest and the expectation is that its collision frequency should be smaller than that of the grass fire as it was determined from the experiment.

The momentum transfer collision frequency could also be estimated from attenuation coefficient versus propagation frequency plots. The attenuation coefficients were calculated from $S$-parameters measured using the network analyser at the times ggsl and les1. However, the method is less accurate than that which uses (11). The plots were observed to have broad absorption peaks near the collision frequencies (see [20]). The peaks for the graphs corresponded to collision frequencies, $5.95 \times 10^{10}$ and $5.78 \times 10^{10} \mathrm{rad} \mathrm{s}^{-1}$, for the grass and eucalyptus litter, respectively (see Figures 5 and 6). The values are not very much different from those obtained from (11). 


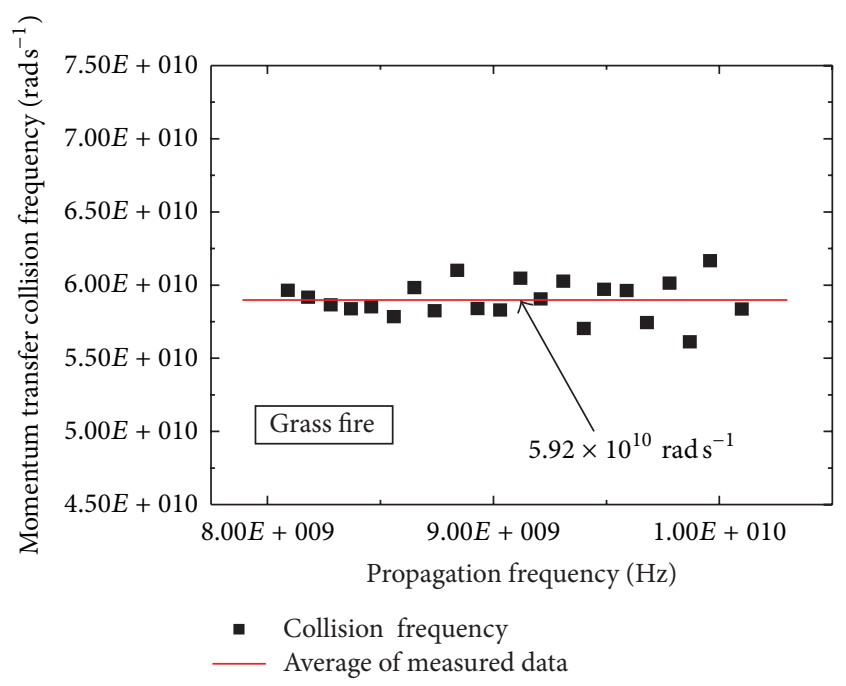

FIGURE 3: Measured collision frequency for the grass fire.

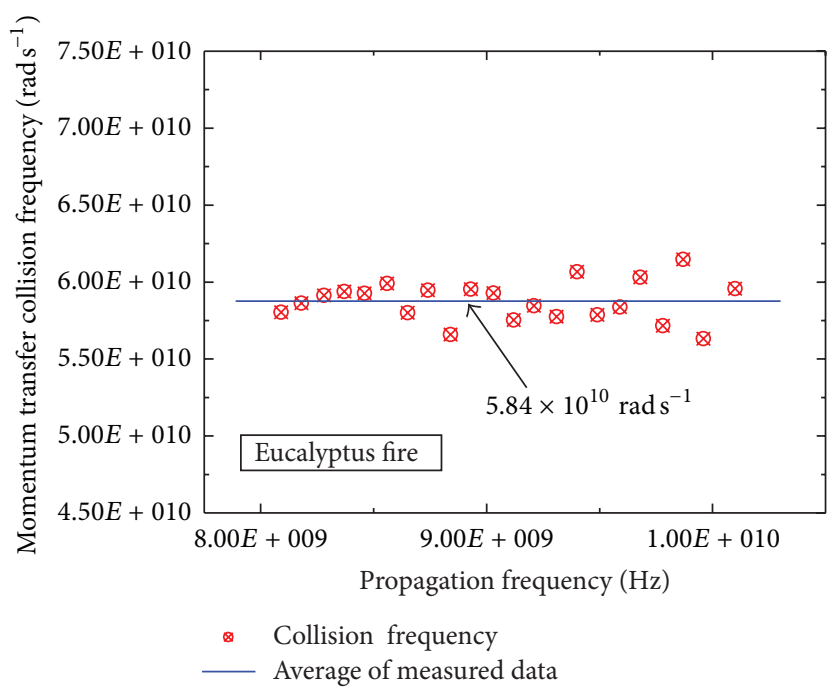

FIgURE 4: Measured collision frequency for eucalyptus fire.

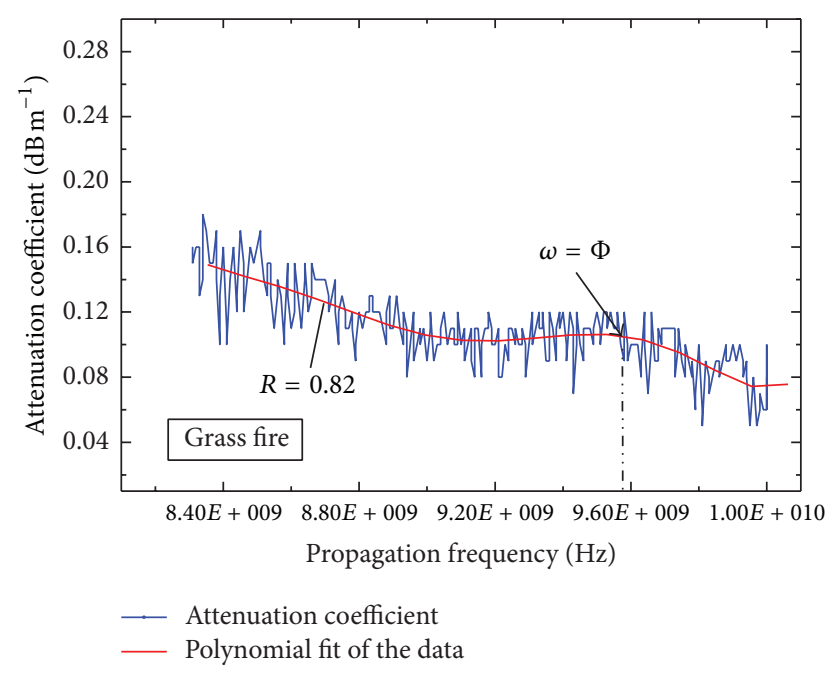

FIGURE 5: Grass fire absorption maxima and collision frequency.

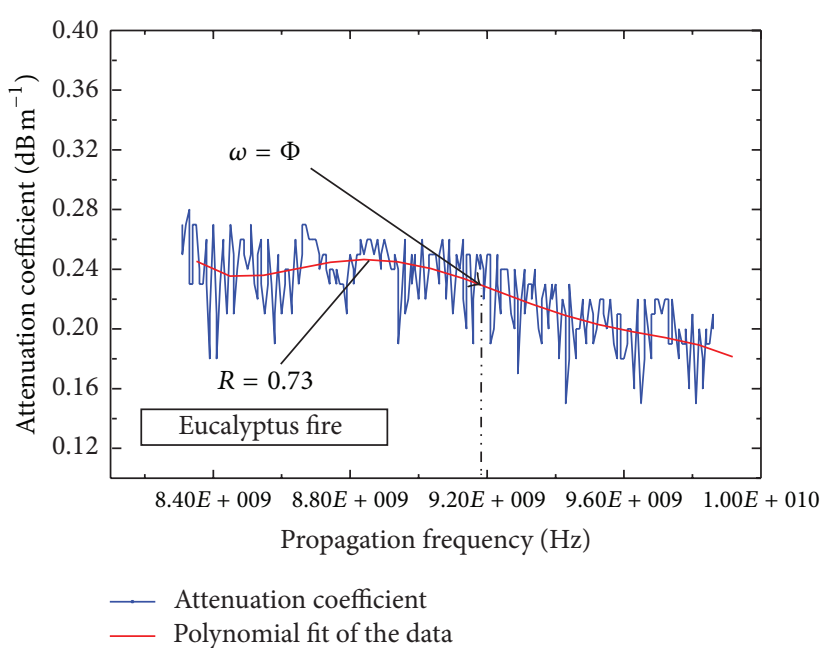

FIGURE 6: Eucalyptus litter fire absorption maxima and collision frequency.

\section{Conclusions}

Transmission of the microwaves was through the hottest region of the fire with significant number of thermal ions (electrons). It also happens to be the region where significant signal amplitude loss by collision occurs. The method proposed was able to measure momentum transfer collision frequency with a fair amount of accuracy.

At the temperature $1006 \mathrm{~K}$, collision frequency of the eucalyptus leaf fire was measured to be $5.84 \times 10^{10} \mathrm{rad} \mathrm{s}^{-1}$ and $5.78 \times 10^{10} \mathrm{rad} \mathrm{s}^{-1}$ by both the direct and graphical methods, respectively. At a much cooler temperature of $839 \mathrm{~K}$, collision frequency for Guinea grass litter was determined to be $5.92 \times$ $10^{10} \mathrm{rad} \mathrm{s}^{-1}$ and $5.95 \times 10^{10} \mathrm{rad} \mathrm{s}^{-1}$ when using the methods, respectively. There was a noticeable average discrepancy of $0.05 \times 10^{10} \mathrm{rad} \mathrm{s}^{-1}$ between the methods. This could be accounted for by errors accrued when identifying the broad absorption peak by the mean value theorem. Compared to collision frequency obtained by calculation using kinetic theory derived expressions, the expression used by [10] gives collision frequencies which are close to the ones determined from $S$-parameters, thus $5.82 \times 10^{10}$ and $6.37 \times 10^{10} \mathrm{rad} \mathrm{s}^{-1}$ for the temperatures 1006 and $839 \mathrm{~K}$, respectively. The other expression from $[15,22]$ gives values which were far from the measured, for example, $8.04 \times 10^{10}$ and $1.34 \times 10^{11} \mathrm{rad} \mathrm{s}^{-1}$, respectively.

Momentum transfer collision of fire plumes depends on the concentration of both the electrons and background gas. For very hot seed flames, it was observed that collision frequencies are much higher, for example, $2.6 \times 10^{11}$ in Schneider and Hofmann's study [24]. The same is also observed in Belcher and Sugden's study [25], where collision frequency for hydrocarbon gas flame was calculated to be $8.8 \times 10^{10} \mathrm{rad} \mathrm{s}^{-1}$. This alkali seeding increased electron densities in both flames hence in high collision frequencies measured. 


\section{Nomenclature}

\begin{tabular}{ll}
$c:$ & Speed of light in vacuum \\
coll: & Collision \\
$d:$ & Propagation path length \\
$D_{g}:$ & Neutral gas diameter \\
$\mathbf{E}:$ & Electric field intensity \\
$\mathbf{E}_{0}:$ & Initial electric field intensity \\
$f:$ & Velocity distribution function \\
$f_{0}:$ & Maxwellian distribution function \\
$\mathbf{f}_{1}:$ & Asymmetric component of $f$ \\
$f_{\mathrm{pr}}:$ & Propagation frequency \\
$\mathrm{J}:$ & Current density in plasma \\
$k_{B}:$ & Boltzmann constant \\
$m_{e}:$ & Electron mass \\
$m_{i}:$ & Mole fraction for ith species \\
$N_{e}:$ & Electron density \\
$N_{g}:$ & Neutral gas density \\
$P:$ & Propagation factor \\
$P_{a}:$ & Atmospheric pressure \\
$q_{e}:$ & Electron charge \\
$Q_{\mathrm{av}}:$ & Average collision cross section \\
$Q_{i}:$ & Collision cross section for $i$ th species \\
$S_{11}:$ & Reflection scattering parameter \\
$S_{21}:$ & Transmission scattering parameter \\
$t:$ & Time \\
$T_{e}:$ & Temperature of electrons in eV \\
$T_{f}:$ & Fire temperature \\
$T_{\mathrm{rf}}:$ & Keference temperature \\
$\mathbf{v}:$ & Electron velocity \\
$v:$ & Magnitude of $v$ \\
$x:$ & Direction of propagation \\
$\bar{v}:$ & Thermal velocity of electrons. \\
& \\
\hline & Reforion
\end{tabular}

\section{Greek Symbols}

$\begin{array}{ll}\gamma: & \text { Propagation constant in fire } \\ \delta: & \text { Normalised electron velocity } \\ \varepsilon_{0}: & \text { Free space dielectric permittivity } \\ \varepsilon_{r}: & \text { Relative dielectric permittivity } \\ \varepsilon^{\prime}: & \text { Real component of } \varepsilon_{r} \\ \varepsilon^{\prime \prime}: & \text { Imaginary component of } \varepsilon_{r} \\ \varphi: & \text { Collision frequency } \\ \lambda_{\mathrm{pr}}: & \text { Propagation wavelength } \\ \sigma: & \text { Complex electric conductivity } \\ \sigma^{\prime}: & \text { Real component of } \sigma \\ \sigma^{\prime \prime}: & \text { Imaginary component of } \sigma \\ \Gamma: & \text { Reflection coefficient } \\ \omega=2 \pi f_{\mathrm{pr}}: & \text { Angular frequency } \\ \omega_{p}: & \text { Fire plasma natural frequency. }\end{array}$

\section{Mathematical}

$i=\sqrt{-1}$ : Imaginary.

\section{Conflict of Interests}

The authors declare that there is no conflict of interests regarding the publication of this paper.

\section{Acknowledgment}

The authors would like gratefully to acknowledge the Department of Electrical Engineering of James Cook University for providing the equipment for $S$-parameter measurement.

\section{References}

[1] J. E. Keeley, H. Safford, C. J. Fotheringham, J. Franklin, and M. Moritz, "The 2007 southern California wildfires: lessons in complexity," Journal of Forestry, vol. 107, no. 6, pp. 287-296, 2009.

[2] M. G. Cruz, A. L. Sullivan, J. S. Gould et al., "Anatomy of a catastrophic wildfire: the black saturday kilmore east fire in victoria, Australia," Forest Ecology and Management, vol. 284, pp. 269-285, 2012.

[3] B. T. Murphy, R. A. Bradstock, M. M. Boer et al., "Fire regimes of Australia: a pyrogeographic model system," Journal of Biogeography, vol. 40, pp. 1048-1058, 2013.

[4] P. M. Attiwill and M. A. Adams, "Mega-fires, inquiries and politics in the eucalypt forest of Victoria south-eastern Australia," Forest Ecology Management, vol. 294, pp. 45-53, 2013.

[5] C. M. Dissanayake, M. N. Halgamuge, K. Ramamohanarao, B. Moran, and P. Farrell, "The signal propagation effects on IEEE 802.15.4 radio link in fire environment," in Proceedings of the 5th International Conference on Information and Automation for Sustainability (ICIAfS '10), pp. 411-414, Colombo, Sri Lanka, December 2010

[6] K. Kinefuchi, I. Funaki, T. Shimada, and T. Abe, "Experimental investigation on microwave interference in full-scale solid rocket exhaust," Journal of Spacecraft and Rockets, vol. 47, no. 4, pp. 627-633, 2010.

[7] D. W. Williams, J. J. Adams, J. S. Batten, G. F. Whitty, and G. T. Richardson, "Operation euroka: an Australian mass fire experiment," Tech. Rep. 386, Defense Standards Laboratory, Maribyrnor, Victoria Australia, 1970.

[8] M. Hata and S. Doi, "Propagation tests for $23 \mathrm{GHz}$ and $40 \mathrm{GHz}$," IEEE Journal on Selected Areas in Communications, vol. 1, no. 4, pp. 658-673, 1983.

[9] J. A. Boan, Radio propagation in fire environments [Ph.D. thesis], University of Adelaide, 2009.

[10] D. Letsholathebe and K. Mphale, "Microwave phase perturbation and ionisation measurement in vegetation fire plasma," IET Microwaves, Antennas and Propagation, vol. 7, pp. 741-745, 2013.

[11] M. Heron and K. Mphale, Radio Wave Attenuation in Bushfires, Tropical Cyclones and Other Severe Atmospheric Conditions, James Cook University.

[12] C. Coleman and J. Boan, "A Kirchhoff Integral approach to radio wave propagation in fire," in Proceedings of the IEEE Antennas and Propagation Society International Symposium (AP-S '07), pp. 3752-3755, Honolulu, Hawaii, USA, June 2007.

[13] X. He, Y. Zhang, J. Chen et al., "Collision absorption and resonance absorption of electromagnetic waves by array plasma," in Proceeding of the 10th International Symposium on Antennas Propagation and EM theory (ISAPE '12), pp. 795-798, Xi'an, China, November 2012.

[14] K. M. Mphale, Radiowave propagation measurement and prediction in Bushfires [Ph.D. thesis], University of James Cook, 2008.

[15] Q. Chen and S. Liu, "Flame imaging in meso-scale porous media burner using electrical capacitance tomography," Chinese Journal of Chemical Engineering, vol. 20, pp. 329-336, 2012. 
[16] C.-X. Yuan, Z.-X. Zhou, J. W. Zhang, X.-L. Xiang, F. Yue, and H.G. Sun, "FDTD analysis of terahertz wave propagation in a hightemperature unmagnetized plasma slab," IEEE Transactions on Plasma Science, vol. 39, no. 7, pp. 1577-1584, 2011.

[17] H. Li, J. Wu, Y.-X. Shi, and J. Wu, "Microwave attenuation characteristics of the dusty plasma produced by solid rocket exhausts," in Proceedings of the 9th International Symposium on Antennas Propagation and EM Theory (ISAPE '10), pp. 371-374, chn, December 2010.

[18] Y.-X. Shi, D.-B. Ge, and J. Wu, "Theoretical analysis of microwave attenuation constant of weakly ionized dusty plasma," Chinese Journal of Geophysics, vol. 50, no. 4, pp. 877-883, 2007.

[19] K. M. Mphale and M. Heron, "Nonintrusive measurement of ionisation in vegetation fire plasma," EPJ Applied Physics, vol. 41, no. 2, pp. 157-164, 2008.

[20] S. Zhang, X. Hu, Z. Jiang, M. Liu, and Y. He, "Propagation of an electromagnetic wave in an atmospheric pressure plasma: numerical solutions," Physics of Plasmas, vol. 13, no. 1, Article ID 013502, pp. 1-7, 2006.

[21] X. P. Lu and M. Laroussi, "Electron density and temperature measurement of an atmospheric pressure plasma by millimeter wave interferometer," Applied Physics Letters, vol. 92, no. 5, Article ID 051501, 2008.

[22] H.S. Uhm, "Properties of plasmas generated by electrical breakdown in flames," Physics of Plasmas, vol. 6, no. 11, pp. 4366-4374, 1999.

[23] T. Baum, L. Thompson, and K. Ghorbani, "Complex dielectric measurements of forest fire ash at X-band frequencies," IEEE Geoscience and Remote Sensing Letters, vol. 8, no. 5, pp. 859-863, 2011.

[24] J. Schneider and F. W. Hofmann, "Absorption and dispersion of microwaves in flames," Physical Review, vol. 116, no. 2, pp. 244249, 1959.

[25] H. Belcher and T. M. Sugden, "Studies on the ionisation produced by metallic salts in flames II. Reactions governed by ionic equilibrium in coal-gas/air flames containing alkali metal salts," Proceedings of the Royal Society of London A, vol. 202, no. 1068, pp. 17-39, 1950. 

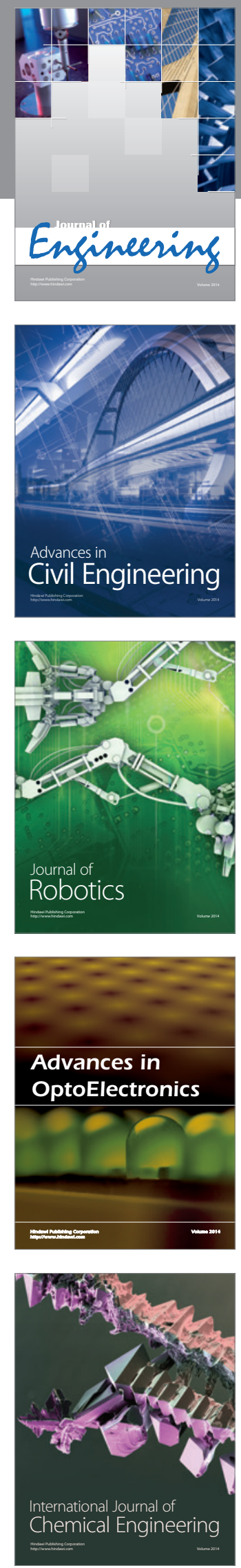

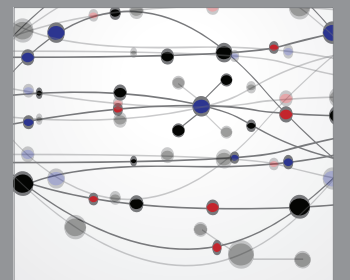

The Scientific World Journal
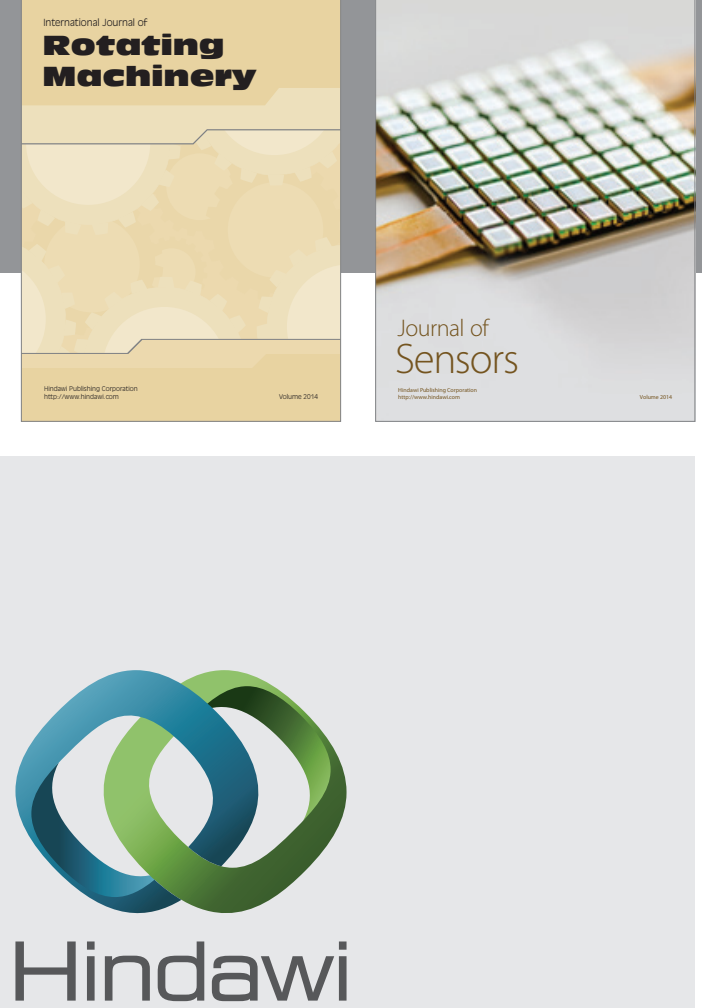

Submit your manuscripts at http://www.hindawi.com
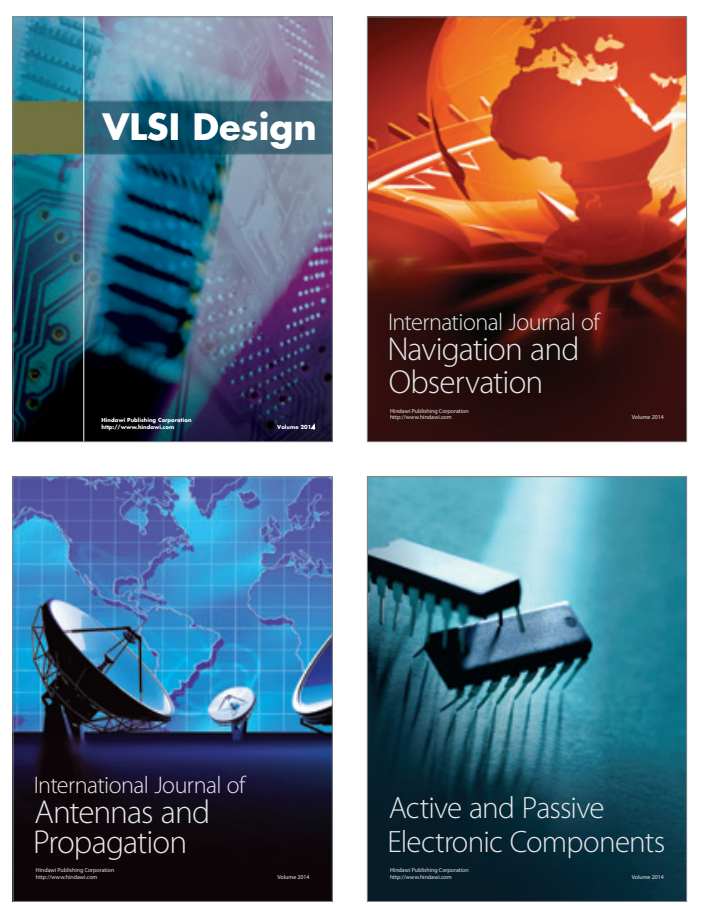
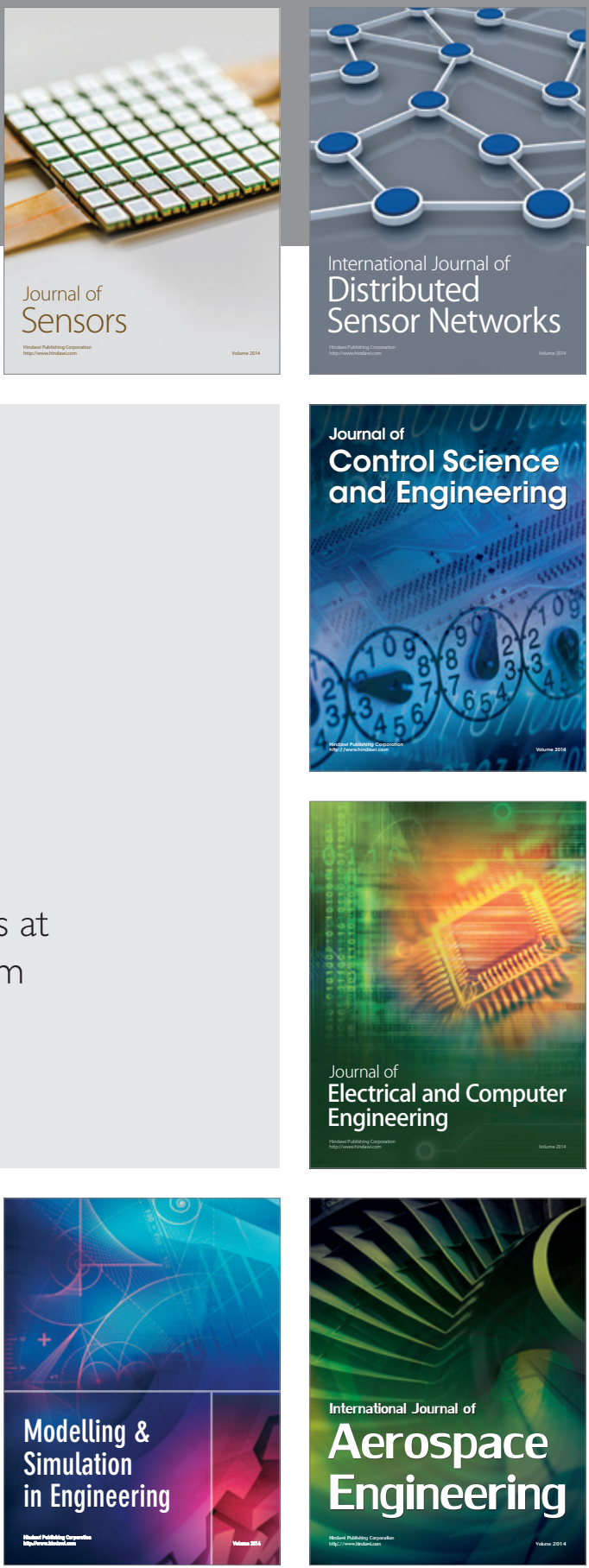

Journal of

Control Science

and Engineering
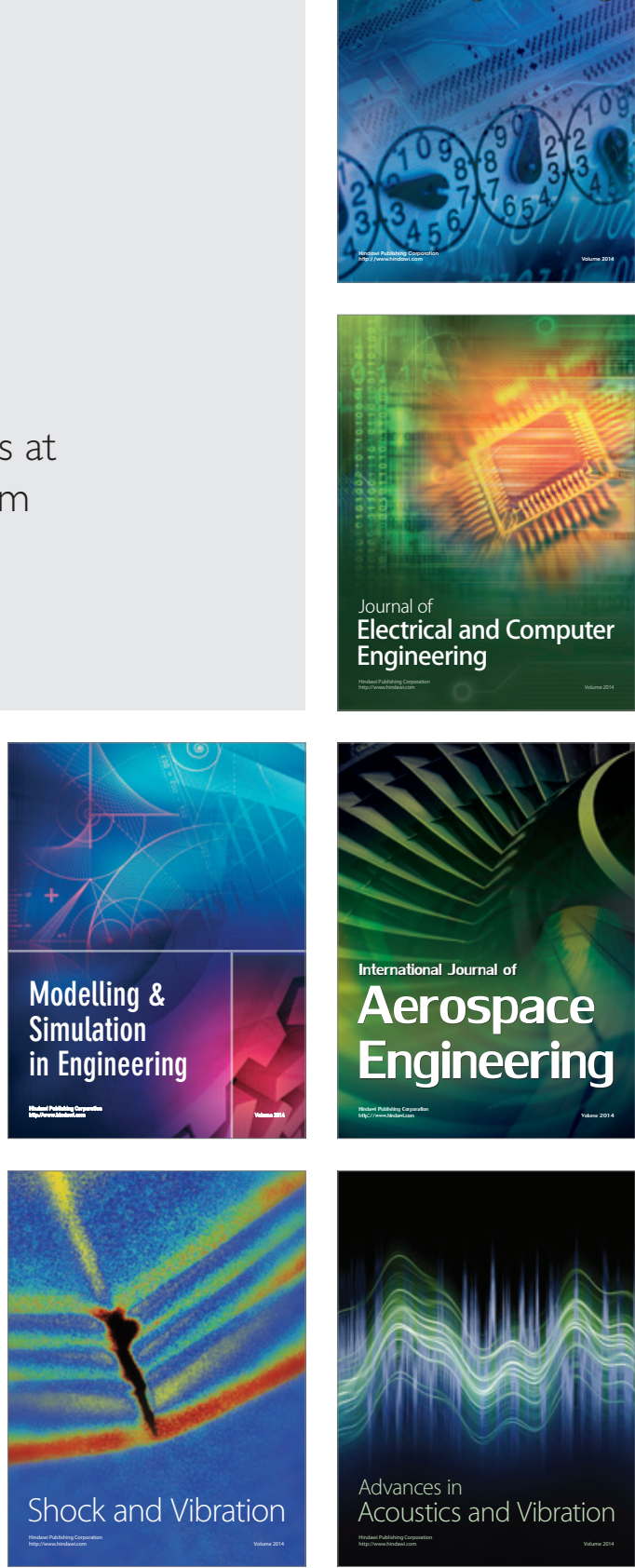